\title{
Research on the Effectiveness of National Language Education in Kindergartens in Yili*
}

\author{
Juanjuan Zhang \\ Yili Normal University \\ Yining, China
}

\begin{abstract}
The National Language Education is an important part of language education in multi-ethnic areas. The study used the WPPSI language scale to test the National Language of 35 ethnic minority children in each of Kindergartens A and B. Participants in kindergarten A took 4 months to enter kindergarten, while participants in kindergarten B took 30 months. Participants in kindergartens $A$ and $B$ came from families with roughly the same cultural background, and both were 6 years old when tested. The test found that the scores of children in kindergarten $B$ on the WPPSI language scale total score and the five sub-scales were significantly higher than those in kindergarten A. Therefore, it can be proved that the longer National Language Education time in kindergartens has achieved substantial results. Finally, the study puts forward some suggestions for promoting National Language learning for minority children from the perspective of kindergartens and families.
\end{abstract}

Keywords-kindergarten; National Language Education; effectiveness

\section{INTRODUCTION}

Mastering the National Language is the responsibility of citizens, and the National Language is very important for personal communication and professional life. Research by Liu Chuqun (2019) shows that the income level of workers is positively correlated with their knowledge of the National Language, the higher the income level, the higher the positive value recognition of the National Language. Cheng Yuanyuan et al. (2019) believe that learning and using the National Language is conducive to promoting exchanges and integration of all ethnic groups and promoting the common development and progress of all ethnic groups. The early childhood stage is a critical period for children's language learning. In this period, learning a second language will not only get twice the result with half the effort, but also better acquire the phonetics of the second language. In recent years, kindergartens in the Yili area of Xinjiang have attached great importance to the National Language Education for young children, but whether such education is effective requires

*Project: This research was funded by the Xinjiang Uygur Autonomous Region Social Science Foundation Youth Project "Study on the Preparation of Xinjiang Ethnic Children's Language Admissions" (2016CJYX118)

This research was also funded by the research project of Yili Normal University "A Study on the Effectiveness of National General Language Education in Kindergartens in Yili Region" (2018YSJC23). standard assessment.

\section{METHODS}

\section{A. Participant Selection}

The study selected two public kindergartens in Yili as a sample. Both kindergartens are mainly ethnic young children. Children's family cultural background and teachers education background are also roughly the same. The sample children in kindergarten A enter kindergarten only 4 months, and the sample children in kindergarten B enter kindergarten 30 months. The two kindergartens A and B each selected 35 infants with an average age of 6 years. The samples covered five ethnic groups: Uygur, Kazakh, Mongolian, Uzbek, and Xibe. The sample does not include Hui and Manchu children, as the National Language is equivalent to their first language.

\section{B. Research Tool}

In this study, the Chinese version of the Wechsler Preschool and Primary Scale of Intelligence (WPPSI) was selected as the assessment tool. In the field of children's language research, WPPSI's language scale is often used as a language testing tool in comparison with other language testing tools. For example, Wang Juan (2017) used WPPSI to measure children's expressive vocabulary and used the PPVT (Peabody Picture Vocabulary Test) measure Children's level of receptive vocabulary development. The Chinese version of WPPSI includes a language scale and an operation scale. The language scale includes five sub-scales of Information, Vocabulary, Arithmetic, Similarity, and Comprehension. Song Jie and Zhu Yuemei (1987) pointed out that the Chinese version of WPPSI has r-values ranging from half reliability, retest reliability, and inter-test reliability, Validity has been tested in the same way as PPVT, Painter's Test, and DDST, the r-values are 0.6, 0.6, and 0.9, indicating that the Chinese version of WPPSI is a reliable tool. Ambreen (2014) indicates that the WPPSI language scale is a good predictor of academic performance. Five language sub-scales require participants to conceptualize speech, store and extract knowledge, and verbal expression during the test. The scale assesses participants' ability to listen to questions, learn from formal and non-formal education, reason with answers, and express ideas loudly. 


\section{RESULTS}

\section{Testing Method}

The study was conducted in a quiet room in the kindergarten using individual test methods, and the manual was strictly followed during the test. When the child does not understand the question, the tester can repeat the question once. If the child's answer is ambiguous, ask the child to explain the "answer" clearly, for example, "tell me more" or something similar. When a child rejects a quiz, the next quiz can be taken before the other quizzes are completed. After all the samples were tested, the data was processed using SPSS17.0.
Here are the differences between five sub-tests of WPPSI language scale for children in kindergartens $\mathrm{A}$ and $\mathrm{B}$.

\section{A. Information Test}

The Information Test is mainly responsible for speech understanding. The unique ability of the scale test is the grasp of common sense, and it also tests children's long-term memory and information. The scope of Information Test includes general astronomy, geography, history, objects, festival knowledge, etc. During the test, young children are asked to say what specific items or facts they know. The difference in the scores of children in A and B kindergarten on the Information Test is shown in the following "Fig. 1":

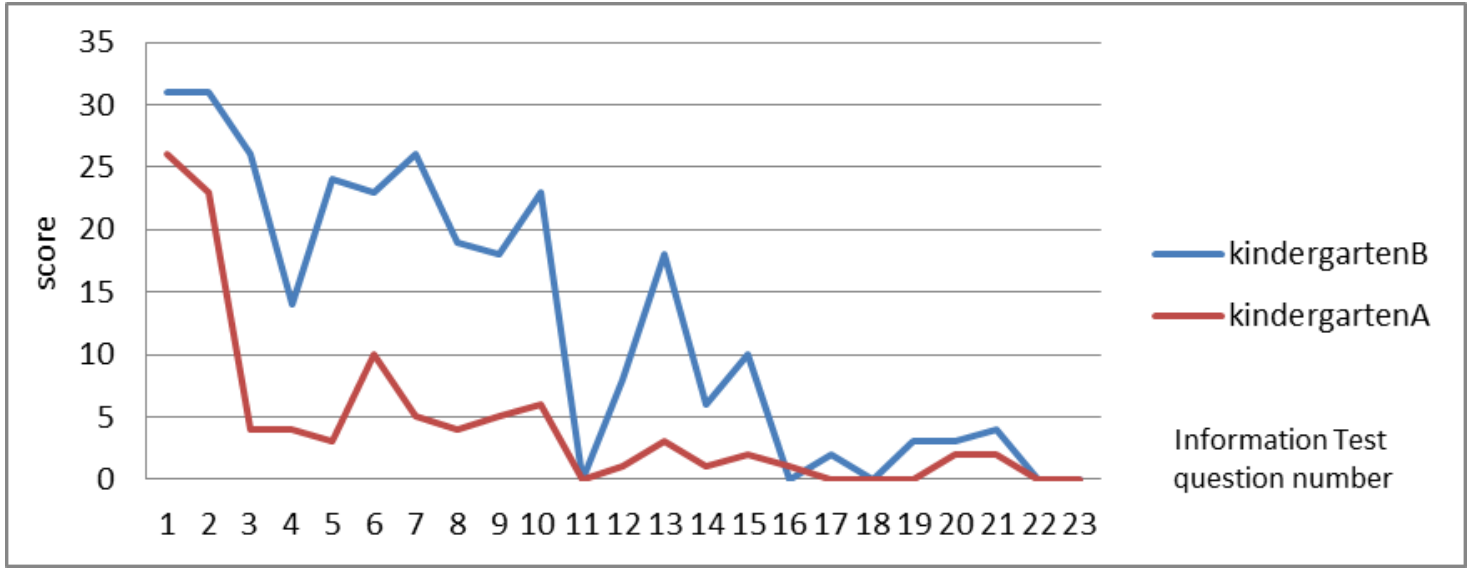

Fig. 1. Differences in scores of A and B kindergarten children in the Information Test.

In the Information Test, children in kindergarten A scored higher than all children in kindergarten B except for the 16 questions, of which there are 11 questions of "stamps", 16 questions of "coin", and 22 questions of "how many things make a dozen?" These questions are not common in children's daily life, so the scores are very low. Questions 1, 2, and 3 scored high in both kindergartens because "nose, ears, and thumb" are familiar body parts for young children. Children in kindergarten B score higher on other topics. This is because children in kindergarten B have more time to learn National Language knowledge in kindergarten.

\section{B. Vocabulary Test}

The Vocabulary Test is mainly loaded with speech understanding factors. The unique ability of the scale test includes language development and word understanding. It also tests the level of abstract thinking, the amount of information, learning ability, long-term memory ability, formation of speech concepts, and speech expression. The test requires children to report the meaning of the words verbally. The difference in the scores of children in A and B kindergarten on the Vocabulary Test is shown in the following "Fig. 2":

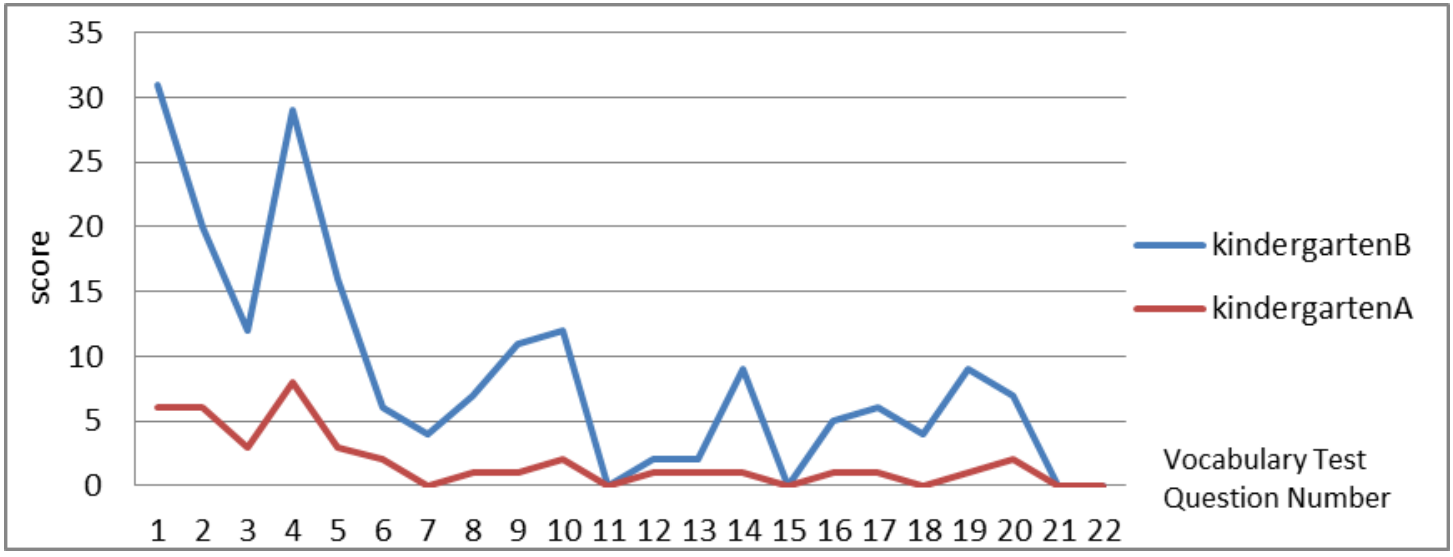

Fig. 2. Differences in scores of A and B kindergarten children in the Vocabulary Test. 


\section{Arithmetic Tests}

Arithmetic Tests are mainly loaded with verbal understanding and anti-distraction factors. The questions are composed of words, the questions are dictated by the main test, the participants listen and mentally calculate the answers, and answer these mathematical questions with language. This test is closely related to school education.

The unique ability of the scale test is arithmetic skills, but also quantitative skills, mental acuity, long-term memory, quantitative reasoning. The difference in the scores of children in A and B kindergarten on the Arithmetic Tests is shown in the following "Fig. 3":

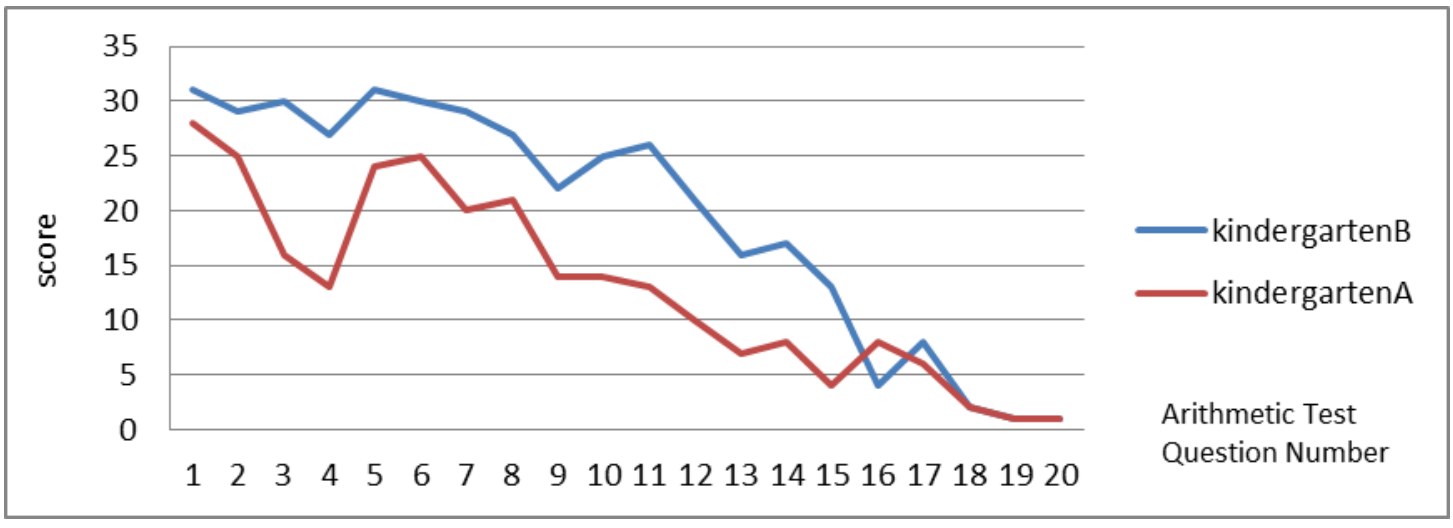

Fig. 3. Differences in scores of A and B kindergarten children in the Arithmetic Tests.

On the whole, the kindergarten children's Arithmetic Tests scores in kindergarten $\mathrm{B}$ are higher than those in kindergarten A. After question 9, the scores of children in both kindergartens have dropped significantly, especially for children in kindergarten $\mathrm{A}$. After the ninth question, the main test no longer presents the questions in pictures, but instead dictates the questions. The children listen and mentally calculate the answers. This is a greater challenge for children in A garden who have a poor level of Mandarin listening. After 16 questions (two dollars for an apple, how much are two apples?) After that, the scores of the two kindergarten children suddenly dropped, because single-digit multiplication and addition and subtraction of more than 10 are difficult for most children around six years old.

\section{Similarity Test}

The Similarity Test is mainly responsible for speech understanding. The unique ability of the scale test is logical abstract thinking. This test also measure children's ability to abstract general rules from special facts. They also test children's ability to distinguish basic and non-essential elements, their ability to form speech concepts, and their ability to express words. When testing, children are mainly required to describe a common feature of the two concepts in language. The difference in the scores of children in A and B kindergarten on the Similarity Test is shown in the following "Fig. 4":

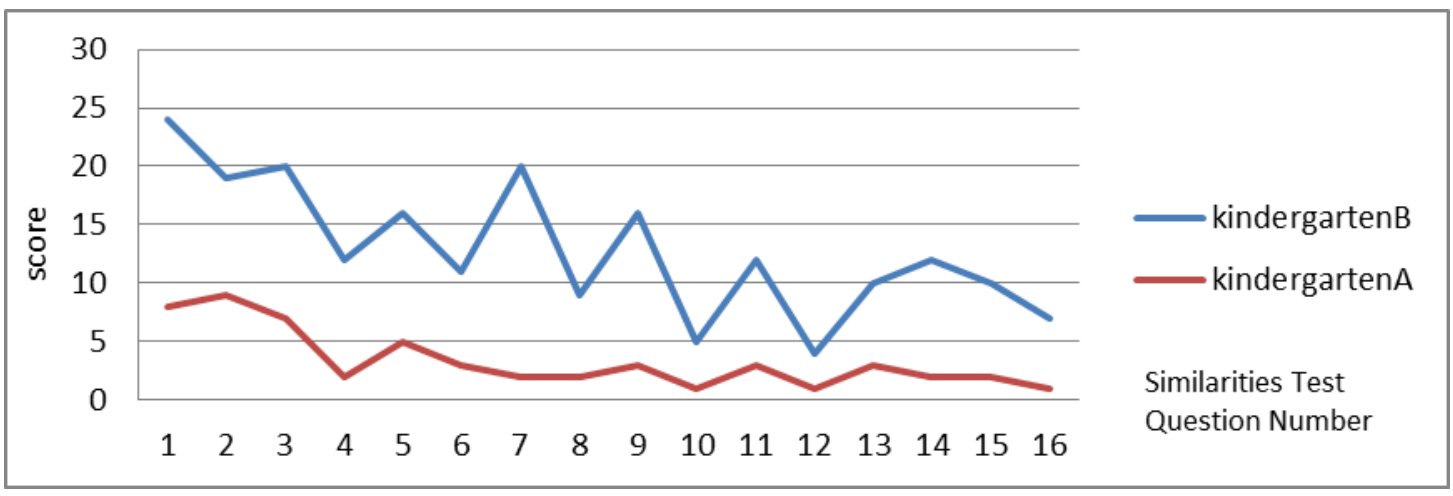

Fig. 4. Differences in scores of A and B kindergarten children in the Similarity Test.

On the whole, the scores of the B-Kindergarten children's Similarity Test are higher than those of A-Kindergarten. The lower-scoring questions are mainly concentrated in the second type of questions (10-16 questions), "What's the 
similarity between $x \times$ and $x \times$ ?" The questions with the lowest scores for both kindergarten children are "What's the similarity between guitar and violin?" Children with low scores may not understand the true intent of the test. In addition, the guitar and violin are not familiar to minority children (minorities have a series of traditional musical instruments that they are familiar with), which may also increase the difficulty for children to summarize.

\section{E. Comprehension Test}

The Comprehension Test is mainly responsible for speech understanding. The unique ability of the scale test includes the proof of practical information, the evaluation and use of past experience, and the ability to understand rules, reasoning, social judgment, and speech expression. Participants were asked to explain why they must follow certain social rules and why they must do so under certain circumstances. The difference in the scores of children in A and B kindergarten on the Comprehension Test is shown in the following "Fig. 5":

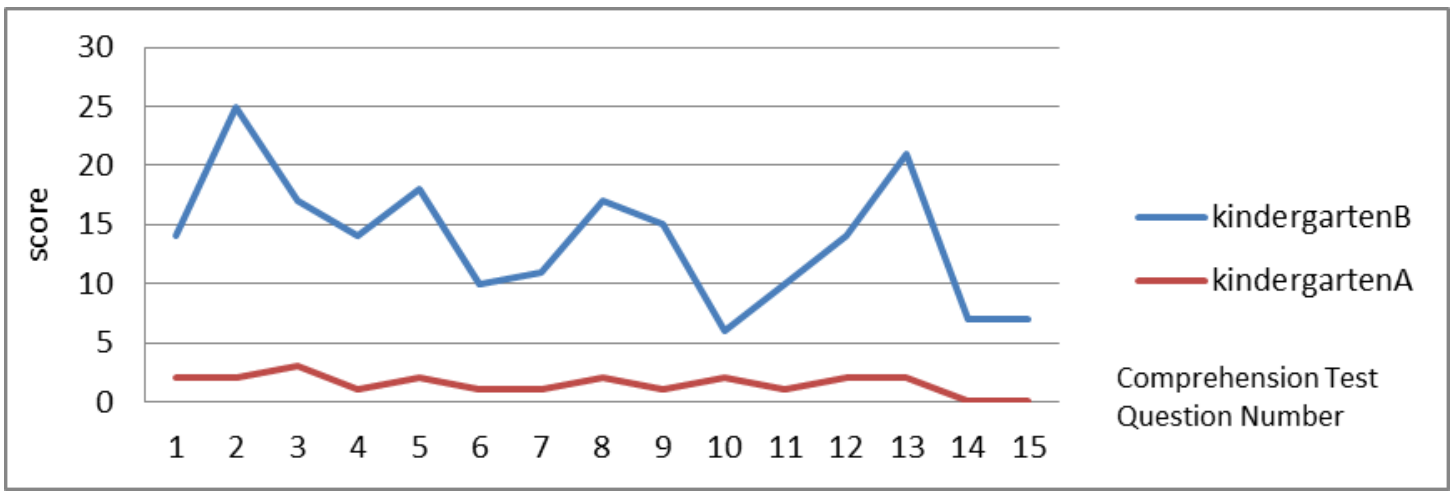

Fig. 5. Differences in scores of A and B kindergarten children in the Comprehension Test.

On the whole, children in kindergarten B scored higher on each question in the Comprehension Test than children in kindergarten A. Children in Kindergarten A scored zero on questions 14 and 15 . This type of question requires participants to explain why they must adhere to certain social rules and make effective adaptations to a situation. Some incorrectly answered children do not know common sense information, for example, they do not know what "bricks" are; some children cannot understand the context of the problem, for example, the title requires comparison of the advantages of "lights and candles", but the children say "use candles during power outages".

\section{CONCLUSION}

On the whole, under the condition of the same family cultural background and the same age at the time of testing, children who entered kindergarten for 2.5 years had higher scores on the total score and five sub-tests than children who only entered kindergarten for 4 months. This shows that the National Language Education for minority children in Yining public kindergartens is effective.

It was learned through interviews with the kindergarten principals that the parents of most children did not speak a National Language word. Therefore, kindergartens are almost the most important environment for these children to be exposed to Mandarin. Based on an interactive view of language learning, children's second language acquisition comes from meaningful conversations with others. Teachers and peers in the kindergarten can provide "positive" content about the second language, such as correct expression habits. , Language basics, etc., can also provide "negative" content, that is, what is impossible or unacceptable in the language learned. These "negative" content can be provided in advance in a variety of forms, such as by teaching grammatical rules, or reactively providing negative feedback, such as explicit correction, recasts, negotiation, metalinguistic comment, etc. Therefore, the National Language level of children who enter kindergarten for two and a half years will be more than that of children who have only entered kindergarten for four months.

The parents of many minority children cannot speak the National Language, which leads to the lack of a National Language environment at home. After children enter kindergarten, teachers often mechanically train children to read National Language vocabulary, such as repeatedly reading common words such as "drinking water and eating." In the process called "naming games" by linguists, children can learn the names of common things and actions, but there are limitations in learning abstract nouns, verbs, and prepositions, which are also reflected in the results of Vocabulary Tests. David Schaeffer (2013) believes that language development is the result of complex interactions between children's physical maturity, cognitive development, and the changing language environment. The acquisition of a second language is especially dependent on the language environment.

To improve the National Language level of Xinjiang minority children requires efforts from both the kindergarten and the family. In kindergarten, a. Children's common sense can be expanded through a rich theme curriculum; b. Promote children's vocabulary acquisition by presenting the sound, form, and meaning of vocabulary at multiple levels and categories; c. Promote children's vocabulary learning by sharing reading and task repetition strategies; d. Improve children's language understanding through meaningful interaction. In the family, parents can watch Mandarin 
programs with children and encourage them to communicate with others in the national language.

\section{REFERENCES}

[1] Chuqun Liu. (2019).Research on the correlation between labor income and National Language cognition. Language Application, 04.82 .

[2] Yuanyuan Cheng. Li Li. Pengyu Wang.(2019).Analysis of Promotion of National Language and Characters Based on CIPP Evaluation Model - Taking Primary School Students in Hetian County, Xinjiang as an Example .Language Application, 03.41.

[3] Juan Wang. Qiuping Shen. (2017). The effect of family literacy environment on children's vocabulary development - the mediating effect of mother language scaffold. Chinese Journal of Clinical Psychology, 25 (04). 751.

[4] Jie Song. Yuemei Zhu. (1987). Pediatric Intelligent Development Examination. Shanghai: Shanghai Science and Technology Press.

[5] Ambreen, S., \& Kamal, A. (2014). Development of norms of the adapted Verbal Comprehension Subtests of WISC-IV for Pakistani children. Journal of Behavioural Sciences, 24(1), 85-97. Retrieved from

http://search.ebscohost.com/login.aspx?direct=true \&db=psyh\&AN=2 014-24024-007\&lang=zh-cn\&site=ehost-live

[6] David Shaffer, Catherine Jeep. (2013). Developmental Psychology. 8th Edition. Translated by Zou Hong et al. Beijing: China Light Industry Press. 